\title{
McCarthy as Scientist and Engineer, with Personal Recollections
}

\author{
Edward Feigenbaum
}

- John McCarthy, professor emeritus of computer science at Stanford University, died on October 24, 2011. McCarthy, a past president of AAAI and an AAAI Fellow, helped design the foundation of today's internet-based computing and is widely credited with coining the term, artificial intelligence. This remembrance by Edward Feigenbaum, also a past president of AAAI and a professor emeritus of computer science at Stanford University, was delivered at the celebration of John McCarthy's accomplishments, held at Stanford on 25 March 2012.

- AI Magazine
I

$\mathrm{n}$ the late 1950s and early 1960s, there were very few people actually doing AI research - mostly the handful of founders (John McCarthy, Marvin Minsky, and Oliver Selfridge in Boston, Allen Newell and Herbert Simon in Pittsburgh) plus their students, and that included me. Everyone knew everyone else, and saw them at the few conference panels that were held. At one of those conferences, I met John. We renewed contact upon his rearrival at Stanford, and that was to have major consequences for my professional life. I was a faculty member at the University of California, Berkeley, teaching the first AI courses at that university, and John was doing the same at Stanford. As Stanford moved toward a computer science department under the leadership of George Forsythe, John suggested to George, and then supported, the idea of hiring me into the founding faculty of the department. Since we were both Advanced Research Project Agency (ARPA) contract awardees, we quickly formed a close bond concerning ARPA-sponsored AI research and graduate student teaching. And the joint intelligence of both of us was quickly deployed in a very rapid and, in retrospect, brilliant decision to hire Les Earnest to be the executive officer of the new Stanford AI Lab that ARPA supported.

John McCarthy's first breakthrough paper was his 1958 Teddington Symposium paper on programs with commonsense reasoning abilities. That paper represented deep theoretical thinking about how to make progress in AI. It also represented the quintessential John McCarthy as scientist. That scientist evolved into greatness, recognized in the citations accompanying some of the world's most prestigious awards. For example, his 1990 National Medal of Science citation says, among other things, "the application of mathematical logic to computer programs 


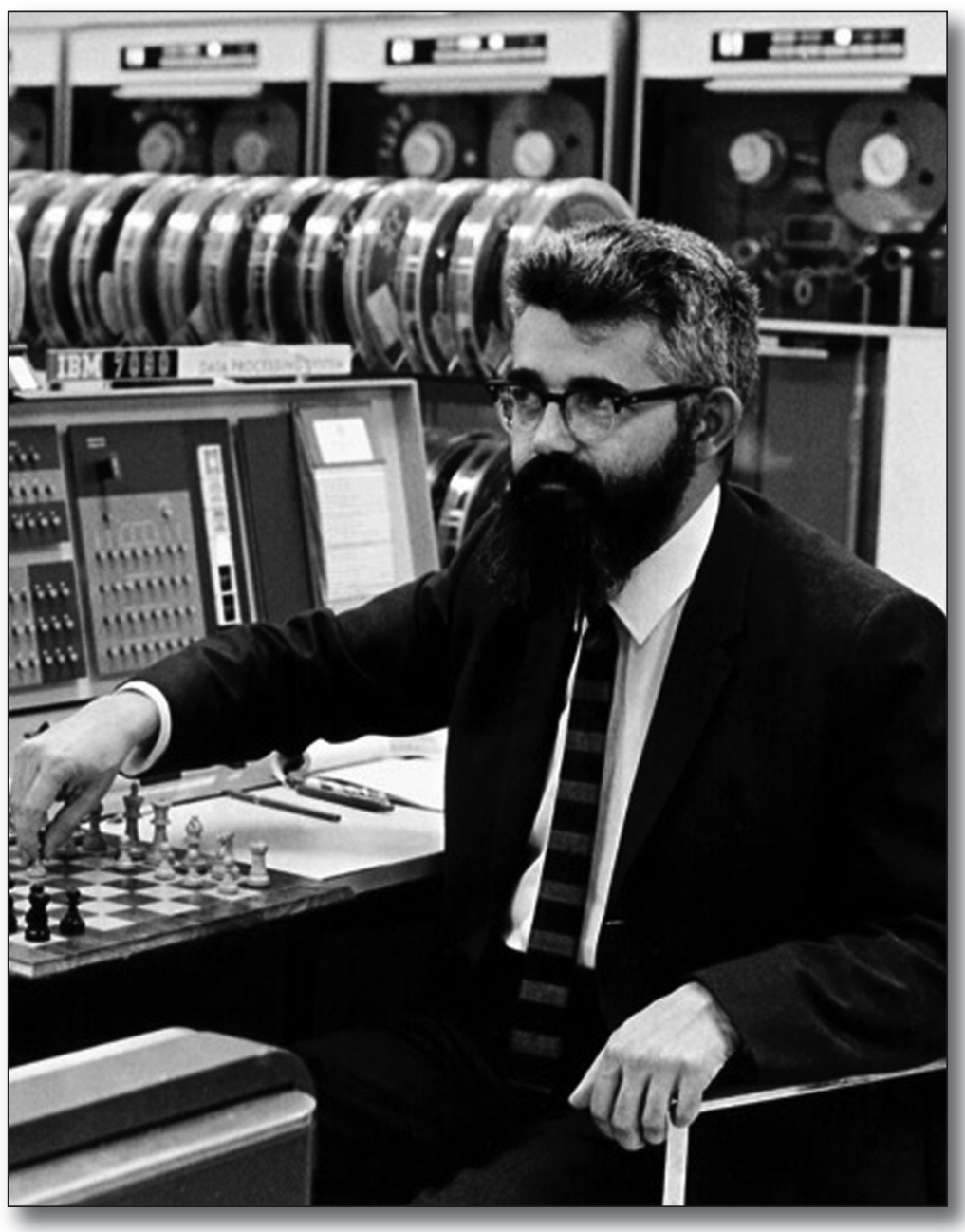

that use commonsense knowledge and reasoning"; his Franklin Institute Award says: "key developments in the application of formal logic to common sense reasoning."

This is the scientific persona with which John saw himself. Yet ... shortly after I arrived at Stanford the first graduate student I met was Raj Reddy, John's first Stanford Ph.D. student. The Reddy work that John was sponsoring and mentoring was as far away from theoretical AI as one could get. Raj was looking at specific wave forms of speech, counting zero-crossings and other features, studying the speech-recognition portion of speech understanding. I met Raj by wandering into a small lab with a PDP-1 time-sharing system that John had a major role in conceiving and designing. This persona was McCarthy as world-class engineer, for which he was famous - in some places more than overshadowing his purely scientific work in theoretical AI. For example, the citation for his Kyoto Prize, one of two highest awards for science and engineering work in Japan, said: "The best known of his accomplishments is the creation of LISP, a programming language for sym- bolic processing," and, "In the field of computer engineering, he proposed the basic concept of the Time Sharing System (TSS) and was involved in its development. This work opened the way toward the development of today's large-scale computers."

There is little space here to relate John's many other engineering facets and contributions. One example, from the mid-1960s: his collaboration with Ed Fredkin and Information International Inc. on the design of a large-scale high-speed graphics system to be interfaced to a time-sharing system resulted in a system that saw pioneering duty at the Stanford AI Lab.

The engineering persona of John McCarthy was as important to the information technology (IT) world as the science persona was to computer science. John was pleased to be known as the father of LISP and the father of time sharing. Yet I think he wished to be remembered by his science persona, his contributions to theoretical AI rather than his contributions to systems and programming languages.

John McCarthy was generous and supportive of a very wide array of activities that he felt used computers in innovative ways with excellence. The AI lab had worked on advanced programming languages, for example SAIL; Kenneth Colby's models of the thought processes of psychiatrists and their patients; John Chowning's and Leland Smith's pioneering work on applications to computer music and the printing of music, leading eventually to the renowned Center for Computer Research in Music and Acoustics (CCRMA) institute at Stanford; Harold Cohen's work on models of art-making behavior; and of course cutting-edge robotics research. For a time, the Stanford AI Lab was, or was close to being, the foremost robotics research lab in the world, with hands, eyes, coordination, and mobility.

McCarthy was quite direct when he gave his thoughts and responses to all issues, even sometimes to the point of bluntness, and was the most honest person I have ever met. He harbored no hidden agendas. No one ever had to speculate or guess about "What does John really mean or really want?" He meant exactly what he said.

John also wrote a great deal, so the future will know his thoughts in some detail. Isaac Newton is supposed to have remarked about contributing by "standing upon the shoulders of giants." Future computer scientists will have the very broad shoulders of John McCarthy upon which to stand as they make their contributions.

Edward Feigenbaum is a professor emeritus of computer science at Stanford University, former president of AAAI, former chief scientist of the Air Force, and founder of the Knowledge Systems laboratory at Stanford. Feigenbaum is often called the "father of expert systems." 